\title{
Utility of Noninvasive Serum Biomarkers of Liver Fibrosis in Infants with Biliary Atresia
}

\author{
Ibrahim A Elhenawy ${ }^{1}$, Heba Samy Ghanem², Mervat M Sultan ${ }^{3}$ and Mostafa Mohamed Sira ${ }^{1 *}$ \\ ${ }^{1}$ Department of Pediatric Hepatology, Gastroenterology and Nutrition, Menofiya University, Egypt \\ ${ }^{2}$ Department of Clinical Pathology, National Liver Institute, Menofiya University, Egypt \\ ${ }^{3}$ Department of Pathology, National Liver Institute, Menofiya University, Egypt
}

Submission: December 17, 2016; Published: February 17, 2017

*Corresponding author: Mostafa M Sira, Department of Pediatric Hepatology, Gastroenterology and Nutrition, National Liver Institute, Menofiya University, 32511 Shebin El-koom, Menofiya, Egypt, Tel: +2-048-222-2740; Fax: +2-048-223-4586; Email: msira@liver-eg.org

Abstract

Background: Biliary Atresia (BA) is the most common cause of chronic cholestasis in infants It is a destructive inflammatory obliterative cholangiopathy that affects varying lengths of both intrahepatic and extrahepatic bile ducts. Even after a successful surgery, scarring of the liver can continue, resulting in cirrhosis and its complications.

Aim: The aim of this study is to evaluate different serological markers derived from routine investigations in the prediction of liver fibrosis in infants with BA.

Methods: This retrospective study included a total of 147 infants with proved diagnosis of BA. We employed six noninvasive scores (FIB-4, FibroQ King's score, APRI, GUCI and AAR). Liver fibrosis was classified into 5 grades. For further descriptive purpose, we arbitrarily divided fibrosis grades into early (F1, F2 and F3) and advanced (F4 and F5) fibrosis.

Results: FIB-4, FibroQ and King's score correlated significantly with fibrosis grade (P values were 0.007 and 0.015 respectively) while there was no significant correlation with other studied scores (P value $>0.05$ ). FIB-4, FibroQ and King's score were significantly higher in patients with advanced fibrosis compared to early fibrosis and at cutoff values of $0.0098,0.0085$ and 0.115 respectively they were able to discriminate those with advanced fibrosis with acceptable sensitivity (61.9\%-64.3\%) and specificity (60.0\%-62.9\%).

Conclusion: FIB-4, FibroQ and King's score, but not APRI, GUCI and AAR, correlated significantly with fibrosis and could predict those with advanced fibrosis with relatively acceptable performance. These markers may be of help in predicting advanced fibrosis and in long term follow up of infants with BA and reduce the need for repeated liver biopsy.

Keywords: AAR; APRI; Biliary atresia; FIB-4; FibroQ; GUCI; King's score; Liver fibrosis; Noninvasive; Serological markers

Abbreviations: BA: Biliary Atresia; AAR: AST/ALT Ratio; ALP: Alkaline Phosphatase; ALT: Alanine Transaminase; APRI: AST-To-Platelet Ratio Index; AST: Aspartate Transaminase; AUROC: Area Under ROC; FIB-4: Fibrosis-4; FibroQ: Fibro-Quotient; GGT: Gammaglutamyl Transpeptidase; GUCI: Göteborg University Cirrhosis Index; INR: International Normalized Ratio; NPV: Negative Predictive Value; PPV: Positive Predictive Value; ROC: Receiver Operating Characterstic

\section{Introduction}

Biliary Atresia (BA) is the most common cause of chronic cholestasis in infants and the most frequent cause for surgery in cholestatic jaundice in this age group. It is a destructive inflammatory obliterative cholangiopathy that affects varying lengths of both intrahepatic and extrahepatic bile ducts [1]. If not treated, BA leads to biliary cirrhosis, hepatic failure and death within the first two years of life [2,3].
The etiology of BA has been a subject of intense investigation. However, the precise etiology remains largely unknown [4]. The initial event may be a viral infection, which targets the biliary epithelium [5]. This is followed by activation of immune cells and release of proinflammatory cytokines that perpetuates the injury and causes biliary destruction, which is followed by collagen deposition to produce the atresia phenotype [6]. Some studies 
suggested the involvement of biliary morphogenesis genes $[7,8]$ or very recently discovered biliary toxin; biliatrisone $[9,10]$.

The principal treatment of BA is based on surgical reconstruction of bile flow by Kasai portoenterostomy. However, such interventions can be insufficient to prevent further hepatic injury. Even after a successful surgery, scarring of the liver can continue, resulting in cirrhosis over the years. This is probably due to the ongoing inflammatory process [11].

Complications of progressive fibrosis and cirrhosis such as esophageal varices may endanger the patient's life and necessitates urgent intervention [11]. Furthermore, the success of Kasai portoenterostomy is largely dependent on the absence of advanced fibrosis or cirrhosis [12]. For that, noninvasive prediction of liver fibrosis in such patients, avoiding the risks of repeated liver biopsy $[13,14]$ and its limitations including sampling error, and inter- and intra-observer variability in interpretation [15], would be of value during monitoring and follow up of this devastating disease [16]. The aim of the current study was to evaluate different serological markers derived from routine laboratory investigations in the prediction of liver fibrosis in infants with BA.

\section{Patients and Methods}

\section{Study population and data collection}

This retrospective study included 147 infants with surgically proved BA attending the Department of Pediatric Hepatology, Gastroenterology and Nutrition in the period between year 2010 and 2015. Preoperative demographic (age and sex), laboratory data including total and direct bilirubin, transaminases (alanine transaminase; ALT and aspartate transaminase; AST), biliary enzymes (gammaglutamyl transpeptidase; GGT and alkaline phosphatase; ALP), total proteins, serum albumin, international normalized ratio (INR) and platelets count were collected. Hepatic histopathological features in the form of portal fibrosis, were also revised. Due to the retrospective nature of the study, an informed consent was not needed. The study was approved by the Research Ethics Committee of the National Liver Institute, Menofiya University, Egypt.

\section{Laboratory investigations}

Fifteen milliliters venous blood samples were taken by sterile venipuncture, without frothing and after minimal venous stasis using disposable syringes. The blood samples were distributed as follows: $5 \mathrm{ml}$ of venous blood were delivered in a vacutainer plain test tube. Blood was left for a sufficient time to clot; serum was then separated after centrifugation at $3000 \mathrm{rpm} / \mathrm{min}$ for $10 \mathrm{~min}$ for liver function tests. Five milliliters of venous blood were delivered in a vacutainer plastic tube containing EDTA for complete blood count (CBC). Five milliliters of venous blood were delivered in a vacutainer plastic tube containing Sodium Citrate for INR. CBC was performed on Sysmex KX-21 (Wakinohamakaigandori, Kobe, Hyogo, Japan). Liver function tests [ALT, AST, albumin, total protein, total bilirubin, direct bilirubin, ALP and GGT] were conducted using Integra 400 autoanalyzer (RocheDiagnostics, Mannheim, Germany). Prothrombin time and INR were conducted using Sysmex CA 1500 coagulometer.

\section{Liver biopsy}

Ultrasonography-guided liver biopsy was done for all patients using a tru-cut needle. Biopsy specimens were fixed in formalin and embedded in paraffin. Five-micron thick sections were cut and stained with Hematoxylin-Eosin, Mason-Trichrome, Orcein and Perls' stains for routine histopathological evaluation. Portal fibrosis was assessed using a semi-quantitative histopathological score as described by Russo et al. [17].

\section{Calculation of the selected non-invasive serological scores}

The employed scores was calculated as follows; AST-toplatelet ratio index (APRI) was calculated according to the formula; APRI = AST / upper limit of normal x $100 /$ platelet count $\left(10^{9} / \mathrm{L}\right)$ [18]; Fibrosis-4 (FIB-4) = Age (years) $\times$ AST $/$ platelet count $\left(10^{9} / \mathrm{L}\right) \times(\mathrm{ALT})^{1 / 2}$ [19]; Fibro-quotient (FibroQ) index using this formula $10 \times$ (age in years $\times$ AST $\times$ INR) $/($ ALT $\times$ platelet count) [20]; King's score using this formula Age (years) x AST (IU/L) x INR/platelet count $\left(10^{9} / \mathrm{L}\right)$ [21]; AST/ALT ratio (AAR) [22]; Göteborg University Cirrhosis Index (GUCI) using the formula (Normalized ASTxINRx100)/platelet count $\left(10^{9} / \mathrm{L}\right)$ [23].

\section{Statistical Analysis}

Descriptive results were expressed as mean \pm standard deviation (mean $\pm \mathrm{SD}$ ) or number and percentage. For quantitative data, significance was tested by Mann-Whitney U-test or Kruskal-Wallis test. Correlation was tested using spearman's test. The cutoff values for optimal clinical performance was determined from the receiver operating characterstic (ROC) curve. The diagnostic performance was measured by the area under ROC (AUROC) and presented as sensitivity specificity, positive predictive value (PPV) and negative predictive value (NPV). Results were considered significant if $\mathrm{P}<0.05$. Statistical analysis was performed using SPSS software version 13 (SPSS Inc, Chicago, IL, USA).

\section{Results}

\section{Study population's characteristics}

The current study included 147 infants with BA. Their mean age was $76 \pm 41$ days and $55 \%$ were females. Other baseline laboratory parameters and histopathological fibrosis grades were as presented in Table 1.

\section{Distribution of serological scores according to fibrosis grades}

The selected scores were compared according the individual fibrosis grades. In all the six scores, the values were at its lowest in F1 and was highest in F5 except for FibroQ and AAR, the 
values were lower than that of F4, yet, there was no significant statistical difference among the different grades of fibrosis (Figure 1). On the other hand, correlation analysis revealed a significant positive correlation of FIB-4, FibroQ and King's scores with fibrosis grades (P values were 0.007 and 0.015 respectively) while there was no significant correlation with the other studied scores ( $\mathrm{P}$ value $>0.05$ ) as shown in Table 2 .

Table 1: Laboratory characteristics of the studied patients.

\begin{tabular}{|c|c|}
\hline Parameter & BA Patients $(\mathrm{N}=147)$ \\
\hline \multicolumn{2}{|c|}{ Liver Function Tests } \\
\hline Total bilirubin (mg/dl) & $11.66 \pm 4.04$ \\
\hline Direct bilirubin (mg/dl) & $7.98 \pm 3.17$ \\
\hline Albumin (g/dl) & $3.29 \pm 0.52$ \\
\hline Alanine transaminase $(\mathrm{U} / \mathrm{L})$ & $141.89 \pm 97.63$ \\
\hline Aspartate transaminase $(\mathrm{U} / \mathrm{L})$ & $229.27 \pm 140.93$ \\
\hline Gamma glutamyle transpeptidase (U/L) & $629.14 \pm 470.26$ \\
\hline Alkaline phosphatase (U/L) & $554.37 \pm 331.12$ \\
\hline International normalized ratio & $1.08 \pm 0.12$ \\
\hline \multicolumn{2}{|c|}{ Fibrosis Grade } \\
\hline Absent or fibrous expansion of some portal tracts (F1) & $4(2.7)$ \\
\hline Fibrous expansion of most portal tracts (F2) & $44(29.9)$ \\
\hline Focal porto-portal bridging (F3) & $57(38.8)$ \\
\hline Marked bridging (F4) & $32(21.8)$ \\
\hline Cirrhosis (F5) & $10(6.8)$ \\
\hline
\end{tabular}

APRI: AST-to-platelet ratio index; FIB-4: Fibrosis-4; FibroQ: Fibro-quotient; AAR: AST/ALT ratio; GUCI: Göteborg University Cirrhosis Index.

A

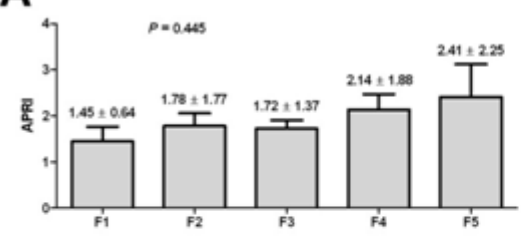

C
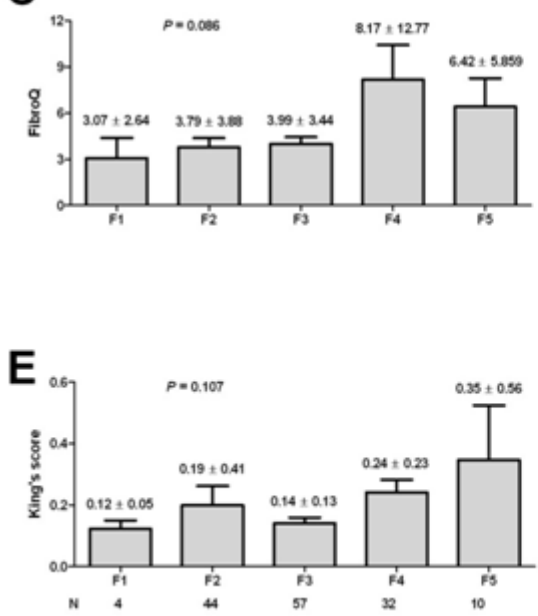

B

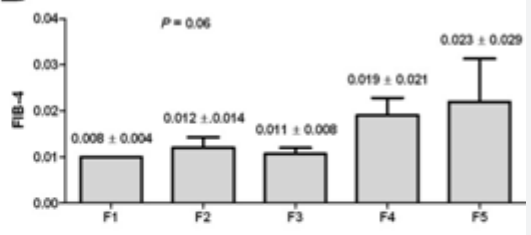

D

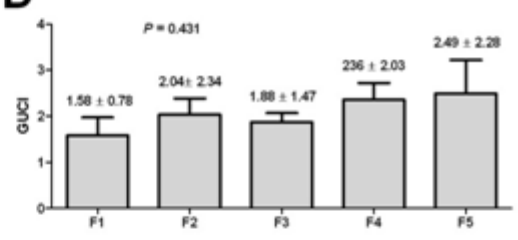

$\mathbf{F}_{2}$

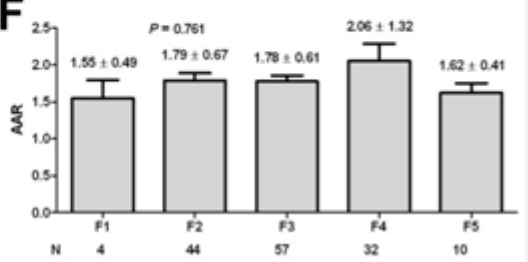

Figure 1: Distribution of serological scores according to fibrosis grades. APRI: AST-to-platelet ratio index; FIB-4: Fibrosis-4; FibroQ: Fibroquotient; AAR: AST/ALT ratio; GUCI: Göteborg University Cirrhosis Index. 
Table 2: Correlation of serological markers with liver fibrosis.

\begin{tabular}{|c|c|c|}
\hline \multirow{2}{*}{ Score } & Fibrosis Grade & \multirow{2}{*}{ P-Value } \\
\cline { 2 - 3 } & $\mathbf{R}$ & \\
\hline APRI & 0.15 & 0.07 \\
\hline FIB-4 & 0.223 & 0.007 \\
\hline FibroQ & 0.201 & 0.015 \\
\hline GUCI & 0.154 & 0.063 \\
\hline King's score & 0.201 & 0.015 \\
\hline AAR & 0.053 & 0.523 \\
\hline
\end{tabular}

APRI: AST-to-platelet ratio index; FIB-4: Fibrosis-4; FibroQ: Fibroquotient; AAR: AST/ALT ratio; GUCl: Göteborg University Cirrhosis Index; AUROC: Area Under Receiver Operating Characterstic.

\section{Comparison between early and advanced fibrosis}

For descriptive purpose, we arbitrarily divided fibrosis grades into early (F1, F2 and F3) and advanced (F4 and F5) fibrosis. Again, FIB-4, FibroQ and King's scores showed a significantly higher values in those with advanced fibrosis ( $P$ values were $0.007,0.017$ and 0.009 respectively) while there was no significant difference using the other studied scores (P value $>0.05$ ) as shown in Table 3 .
Table 3: Comparison of different scores between early and advanced fibrosis.

\begin{tabular}{|c|c|c|c|}
\hline \multirow{2}{*}{ Score } & $\begin{array}{c}\text { Early } \\
\text { fibrosis }\end{array}$ & $\begin{array}{c}\text { Advanced } \\
\text { fibrosis }\end{array}$ & \multirow{2}{*}{ P-value } \\
\cline { 2 - 3 } & $\mathbf{F}$ (F1, F2, F3) & (F4, F5) & \multirow{2}{*}{-va } \\
\cline { 2 - 3 } & $\mathbf{n = 1 0 5}$ & $\mathbf{n}=\mathbf{4 2}$ \\
\hline APRI & $1.74 \pm 1.53$ & $2.2 \pm 1.95$ & 0.08 \\
\hline FIB-4 & $0.011 \pm$ & $0.019 \pm$ & \multirow{2}{*}{0.007} \\
\hline FibroQ & $0.011 \pm 0.01$ & $0.01 \pm 0.03$ & 0.017 \\
\hline GUCI & $1.93 \pm 1.86$ & $2.39 \pm 2.07$ & 0.069 \\
\hline King's score & $0.16 \pm 0.28$ & $0.27 \pm 0.33$ & 0.009 \\
\hline AAR & $1.77 \pm 0.63$ & $1.95 \pm 1.18$ & 0.637 \\
\hline
\end{tabular}

APRI: AST-to-platelet ratio; FIB-4: Fibrosis-4; FibroQ: Fibro-quotient; AAR: AST/ALT ratio; GUCI: Göteborg University Cirrhosis Index.

\section{Performance of FIB-4, FibroQ and King's scores in discriminating advanced fibrosis}

The three scores (a cutoff value of 0.0098 for FIB-4; 0.0085 for FibroQ and 0.115 for King's score) showed nearly a comparable performance in discriminating advanced fibrosis (Table 4).

Table 4: Clinical performance of serological scores in discriminating early from advanced fibrosis.

\begin{tabular}{|c|c|c|c|c|c|c|c|}
\hline Score & AUROC & Cutoff & P-value & Sensitivity & Specificity & PPV & NPV \\
\hline FIB-4 & 0.644 & 0.0098 & 0.007 & 61.9 & 61.9 & 35.4 & 86.2 \\
\hline FibroQ & 0.626 & 0.0085 & 0.017 & 64.3 & 60.0 & 35.1 & 60.7 \\
\hline $\begin{array}{c}81.5 \text { King's } \\
\text { score }\end{array}$ & 0.637 & 0.115 & 0.009 & 64.3 & 62.9 & 40.9 & 81.5 \\
\hline
\end{tabular}

FIB-4: Fibrosis-4; FibroQ: Fibro-quotient.

\section{Discussion}

The prognosis of chronic cholestatic diseases depends, in part, on the extent of liver fibrosis [24,25], while it markedly influences the outcome of Kasai protoenterostomy in infants with BA [12]. In addition, it identifies those in need of liver transplantation whether in those who performed a previous Kasai operation or not [26,27] For that follow up of fibrosis progression is of utmost importance. Liver biopsy, being the gold standard in assessment of liver fibrosis, is not largely accepted when repeated, especially in the pediatric population. For that , the use of noninvasive predictor of liver fibrosis is needed $[28,29]$.

Several noninvasive markers and scores have been applied satisfactorily in hepatitis C virus [18] and non-alcoholic fatty liver diseases [30], while studies on its use in BA are very limited. APRI score has been used in predicting liver fibrosis in BA. Yet, the results are contradictory. Kim et al. [31] reported that APRI significantly discriminated F3 and F4 Metavir score in infants with BA. AUROC for $\mathrm{F} \geq 3$ and $\mathrm{F}=4$ were 0.92 and 0.91 , respectively. Distinct optimal cutoff values of APRI for $F \geq 3$ and $F=4$ were obtained (1.01 and 1.41, respectively). In addition, Grieve et al. [16] using a cutoff value of 1.22 [AUC 0.83] showed a sensitivity of $75 \%$ and a specificity of $84 \%$ for macroscopic cirrhosis. Native liver survival was significantly different but improved only for those with the lowest APRI quartile $(\mathrm{P}=0.009)$. Similar results were also reported by Yang et al. [32].

On the other hand, Lind et al. [33] found that APRI did not significantly differ in various fibrosis Metavir scores $(P=0.89)$ 
and was not correlated with transplant-free survival $(\mathrm{r}=0.08$; $\mathrm{P}=0.67$ ) in infants with $\mathrm{BA}$. Our results are in agreement with that of Lind et al where APRI value neither differ significantly with different Russo fibrosis grades $(\mathrm{P}=0.445)$ nor correlated with fibrosis ( $\mathrm{r}=0.15 ; \mathrm{P}=0.07)$. Nonetheless, APRI values increased successively as fibrosis increases with its lowest in F1 and highest in F5.

Other scores have been used in predicting fibrosis in HCV, all of which are dependent on the routine laboratory tests regularly performed in these patients. Leung et al. [34] found that APRI performed better than FIB-4 in predicting fibrosis studied in children with cystic fibrosis liver disease. In the current study, contrary to APRI, FIB-4 was significantly correlated with fibrosis in $\mathrm{BA}(\mathrm{P}=0.007)$ and was significantly higher in those with advanced fibrosis (Russo F4 and F5; P=0.007). With AUROC of 0.644 , FIB-4 could predict advanced fibrosis with $61.9 \%$ sensitivity and $61.9 \%$ specificity. On the other hand, Chen et al. [35] reported that FIB-4 failed to correlate with fibrosis stage. This may be due to the small number of patients in Chen's study $(\mathrm{n}=24)$ compared to our study $(\mathrm{n}=147)$.

GUCI and AAR were able to predict fibrosis in HCV and hepatocellular carcinoma in addition to predicting response to antiviral therapy [36-38]. In our study, both scores were not correlated with liver fibrosis ( $\mathrm{P}=0.063$ and 0.523 for GUCI and AAR respectively) and could not discriminate advanced from early fibrosis. Unfortunately, there are no reported studies for their use in BA.

On the other hand, FibroQ and King's score showed a significant positive correlation with fibrosis grade $(\mathrm{P}=0.015$ for both) and at a cutoff value of 0.085 and 0.115 respectively, both could discriminate advanced fibrosis from early fibrosis with comparable sensitivity (64.3\% for both) and specificity $(60.0 \%$ and $62.9 \%$ respectively). King's score has been used in assessing fibrosis in chronic hepatitis B [39] and hepatitis C [21] but no reports about its use in predicting fibrosis in BA. Combining the three scores (FIB-4, FibroQ and King's score) did not improve the performance compared to the performance of each score individually. Although statistically significant, the performance of these scores was found to be better in adult studies with chronic hepatitis $\mathrm{C}$. This may be due to the fibrogenic nature of BA and the relatively high platelet counts even in cases with advanced fibrosis [40] which may influence the performance of platelet count-based scores.

In conclusion, FIB-4, FibroQ and King's, but not APRI, GUCI or AAR, correlated significantly with fibrosis grade in infants with BA. These noninvasive serological markers, which are derived from simple routine laboratory tests, may be of help in predicting advanced fibrosis and in long term follow up of infants with BA, and minimize the need for repeated follow up liver biopsies.

\section{Funded by}

National Liver Institute, Menofiya University, Egypt, without any particular role in the study design, recruitment of individuals, data analysis or the writing of the manuscript.

\section{References}

1. Karakayali H, Sevmis S, Ozcelik U, Ozcay F, Moray G, et al. (2008) Liver transplantation for biliary atresia. Transplant Proc 40(1): 231-233.

2. Tiao MM, Tsai SS, Kuo HW, Chen CL, Yang CY (2008) Epidemiological features of biliary atresia in Taiwan, a national study 1996-2003. J Gastroenterol Hepatol 23(1): 62-66.

3. Mieli-Vergani G, Vergani D (2009) Biliary atresia. Semin Immunopathol 31(3): 371-381.

4. Moreira RK, Cabral R, Cowles RA, Lobritto SJ (2012) Biliary atresia: a multidisciplinary approach to diagnosis and management. Arch Pathol Lab Med 136(7): 746-760.

5. Bessho K, Bezerra JA (2011) Biliary atresia: will blocking inflammation tame the disease?. Annu Rev Med 62: 171-185.

6. Srivastava A (2011) Biliary atresia and inflammation: from pathogenesis to prognosis. Trop Gastroenterol 32(1): 1-3.

7. Mezina A, Karpen SJ (2015) Genetic Contributors and Modifiers of Biliary Atresia. v Dig Dis 33(3): 408-414.

8. Ningappa M, Min J, Higgs BW, Ashokkumar C, Ranganathan S, et al. (2015) Genome-wide association studies in biliary atresia. Wiley Interdiscip Rev Syst Biol Med 7(5): 267-273.

9. Davenport M (2016) Biliary atresia: From Australia to the zebrafish. J Ped Surg 51(2): 200-205.

10. Waisbourd Z, Orith, Koh H, Tsai S, Lavrut PM, et al. (2016) The toxin biliatresone causes mouse extrahepatic cholangiocyte damage and fibrosis through decreased glutathione and SOX17, Hepatology. Hepatology 64(3): 880-893

11. van Heurn LE, Saing H, Tam PK (2004) Portoenterostomy for biliary atresia: long-term survival and prognosis after esophageal variceal bleeding. J Ped Surg 39(1): 6-9.

12. Webb NL, Jiwane A, Ooi CY, Nightinghale S, Adams SE, et al. (2016) Clinical significance of liver histology on outcomes in biliary atresia. J Paediatr Child Health.

13. Bravo AA, Sheth SG, Chopra S (2001) Liver biopsy, N Engl J Med 344(7): 495-500.

14. Thampanitchawong P, Piratvisuth T (1999) Liver biopsy: complications and risk factors. World J Gastroenterol 5(4): 301-304.

15. Regev A, Berho M, Jeffers LJ, Milikowski C, Molina EG, et al. (2002) Sampling error and intraobserver variation in liver biopsy in patients with chronic HCV infection. Am J Gastroenterol 97(10): 2614-2618.

16. Grieve A, Makin E, Davenport M (2013) Aspartate aminotransferaseto-platelet ratio index (APRi) in infants with biliary atresia: prognostic value at presentation. J Ped Surg 48(4): 789-795.

17. Russo P, Magee JC, Boitnott J, Bove KE, Raghunathan T, et al. (2011) Design and validation of the biliary atresia research consortium histologic assessment system for cholestasis in infancy, Clin Gastroenterol Hepatol 9(4): 357-362 e352.

18. Wai CT, Greenson JK, Fontana RJ, Kalbfleisch JD, Marrero JA, et al. (2003) A simple noninvasive index can predict both significant fibrosis and cirrhosis in patients with chronic hepatitis C. Hepatology 38(2): 518-526. 
19. Holmberg SD, Lu M, Rupp LB, Lamerato LE, Moorman AC, et al. (2013) Noninvasive serum fibrosis markers for screening and staging chronic hepatitis $C$ virus patients in a large US cohort. Clin Infect Dis 57(2): 240-246.

20. Hsieh YY, Tung SY, Lee IL, Lee K, Shen CH, et al. (2009) FibroQ: an easy and useful noninvasive test for predicting liver fibrosis in patients with chronic viral hepatitis. Chang Gung Med J 32(6): 614-622.

21. Cross TJ, Rizzi P, Berry PA, Bruce M, Portmann B, et al. (2009) King's Score: an accurate marker of cirrhosis in chronic hepatitis C. Eur J Gastroenterol Hepatol 21(7): 730-738.

22. Williams A, Hoofnagle JH (1988) Ratio of serum aspartate to alanine aminotransferase in chronic hepatitis. Relationship to cirrhosis Gastroenterology 95(3): 734-739.

23. Fouad SA, Esmat S, Omran D, Rashid L, Kobaisi MH (2009) Citation of This Article. World J Gastroenterol 15(28): 3511-3515.

24. Dickson ER, Murtaugh PA, Wiesner RH, Grambsch PM, Fleming TR, et al. (1992) Primary sclerosing cholangitis: refinement and validation of survival models. Gastroenterology 103(6): 1893-1901.

25. Roll J, Boyer JL, Barry D, Klatskin G (1983) The prognostic importance of clinical and histologic features in asymptomatic and symptomatic primary biliary cirrhosis. N Engl J Med 308(1): 1-7.

26. Shteyer E, Ramm GA, Xu C, White FV, Shepherd RW (2006) Outcome after portoenterostomy in biliary atresia: pivotal role of degree of liver fibrosis and intensity of stellate cell activation. J Pediatr Gastroenterol Nutr 42(1): 93-99.

27. Weerasooriya VS, White FV, Shepherd RW (2004) Hepatic fibrosis and survival in biliary atresia. J Pediatr 144(1): 123-125.

28. Afdhal NH, Nunes D (2004) Evaluation of liver fibrosis: a concise review. Am J Gastroenterol 99(6): 1160-1174.

29. Martinez SM, Crespo G, Navasa M, Forns X (2011) Noninvasive assessment of liver fibrosis. Hepatology 53(1): 325-335.

30. Kruger FC, Daniels CR, Kidd M, Swart G, Brundyn K, et al. (2011) APRI: a simple bedside marker for advanced fibrosis that can avoid liver biopsy in patients with NAFLD/NASH. S Afr Med J 101(7): 477-480.
31. Kim SY, Seok JY, Han SJ, Koh H (2010) Assessment of liver fibrosis and cirrhosis by aspartate amino transferase-to-platelet ratio index in children with biliary atresia. J Pediatr Gastroenterol Nutr 51(2): 198202.

32. Yang LY, Fu J, Peng XF, Pang SY, Gao KK, et al. (2015) Validation of aspartate aminotransferase to platelet ratio for diagnosis of liver fibrosis and prediction of postoperative prognosis in infants with biliary atresia. World J Gastroenterol 21(19): 5893-5900.

33. Lind R, Verkade H, Porte R, Hulscher J (2012) Aspartate transaminaseto-platelet ratio index is not correlated with severity of fibrosis or survival in children with biliary atresia. J Pediatr Gastroenterol Nutr 54(5): 698.

34. Leung DH, Khan M, Minard CG, Guffey D, Ramm LE, et al. (2015) Aspartate aminotransferase to platelet ratio and fibrosis-4 as biomarkers in biopsy-validated pediatric cystic fibrosis liver disease. Hepatology 62(5): 1576-1583.

35. Chen S, Liao B, Zhong Z, Zheng Y, Liu B, et al. (2016) Supersonic shearwave elastography in the assessment of liver fibrosis for postoperative patients with biliary atresia. Sci Rep 6 .

36. Yosry A, Fouad R, Alem SA, Elsharkawy A, El-Sayed M, et al. (2016) FibroScan, APRI, FIB4, and GUCI: Role in prediction of fibrosis and response to therapy in Egyptian patients with HCV infection. Arab J Gastroenterol 17(2): 78-83.

37. Mobarak L, Omran D, Nabeel MM, Zakaria Z (2016) Fibro markers for prediction of hepatocellular carcinoma in Egyptian patients with chronic liver disease, J Med Virol.

38. Andrés-Otero MJ, De-Blas-Giral I, Puente-Lanzarote JJ, Serrano-Aulló T, Morandeira MJ, et al. (2016) Multiple approaches to assess fourteen non-invasive serum indexes for the diagnosis of liver fibrosis in chronic hepatitis C patients. Clin Biochem 49(7-8): 560-565.

39. Marpaung YA, Sembiring J, Zain LH (2016) Accuracy of Liver Fibrosis Degree Based on King's Score to FibroScan in Chronic Hepatitis B, Indonesian J Gastroenterol. Hepatol. Dig Endo 17(1): 10-15.

40. Sira MM, Sira AM, Ehsan NA, Mosbeh A (2015) P-Selectin (CD62P) Expression in Liver Tissue of Biliary Atresia: A New Perspective in Etiopathogenesis. J Pediatr Gastroenterol Nutr 61(5): 561-567.

Your next submission with JuniperPublishers
will reach you the below assets
- Quality Editorial service
- Swift Peer Review
- Reprints availability
- E-prints Service
- Manuscript Podcast for convenient understanding
- Global attainment for your research
- Manuscript accessibility in different formats
( Pdf, E-pub, Full Text, Audio)
- Unceasing customer service
Track the below URL for one-step submission
https://juniperpublishers.com/online-submission.php

